\title{
MOVIMIENTO FICTICIO EN GRIEGO ANTIGUO: TRAS LAS HUELLAS DEL VIAJERO (IN)VISIBLE
}

\author{
Julián MÉndez Dosuna \\ Universidad de Salamanca
}

\begin{abstract}
RESUMEN
El movimiento ficticio es un fenómeno muy extendido en las lenguas del mundo y este artículo trata de ser una caracterización global de sus diversas manifestaciones en griego antiguo. El movimiento ficticio propiamente dicho consiste en una metonimia por la que un Trayecto se concibe como un Agente que se desplaza (la carretera va a Atenas). El viajero implícito en esas oraciones aparece a menudo en forma de participio en dativo o genitivo que expresa un Experimentador, o en forma de $2^{a}$ persona genérica. El movimiento ficticio desempeña a menudo un papel importante en oraciones comparativas que describen un Trayecto que conduce a un lugar, y también explica el uso del acusativo con valor de Trayecto en algunos sintagmas preposicionales, que -contra lo esperado-se combinan con verbos estáticos.
\end{abstract}

Palabras clave: griego antiguo, movimiento ficticio, verbos estáticos y dinámicos, preposiciones.

\section{ABSTRACT}

Fictive motion is a widespread phenomenon in the languages of the world, and this paper is meant to be an overall characterization of its different manifestations in Ancient Greek. Fictive motion proper involves a metonymy whereby a Path is conceived of as an Agent who moves (e.g. The road goes to Athens). The traveler implicit in these sentences often appears as a participle in the dative or genitive to express an Experiencer, or as a generic second person. Fictive motion often plays an important role in comparative sentences that describe a Path leading to a place, and it also explains the use of the accusative expressing Path in some prepositional phrases that -contrary to expectation- are combined with static verbs.

Key Words: Ancient Greek, fictive motion, static and dynamic verbs, prepositions.

\section{INTRODUCCIÓN}

En 1956 Salvador Dalí pintó «Naturaleza muerta viviente» (Still life fast moving en inglés). En el universo surrealista de Dalí, las entidades estáticas en el mundo real aparecen dotadas de movimiento mientras que las dinámicas se representan como estáticas. No es difícil establecer 
una analogía con un un fenómeno muy difundido en las lenguas del mundo: el «movimiento ficticio» también llamado «imaginario», «subjetivo» 0 «virtual» 1 .

Este «movimiento inmóvil» ha recibido renovada atención en los últimos años, sobre todo por parte de estudiosos vinculados a la Lingüística Cognitiva (Matsumoto 1996, Langacker 1999, Talmy 1996 ～2000).

\section{MOVIMIENTO INMÓVIL}

Me propongo examinar aquí algunas de las características del movimiento ficticio en el griego antiguo, donde este fenómeno se manifiesta de formas diversas. El grado más elevado de ficcionalidad se da en la metonimia antropomórfica que dota de capacidad motriz a un Trayecto $(\S 3)$. Otras veces hay un viajero virtual que remite a un movimiento real y que puede asumir distintas identidades. La mayor visibilidad se da en la $2^{a}$ persona genérica $(\$ 5)$. Una situación intermedia son los participios en dativo ( «dativo de punto de vista») o genitivo $(\$ 4)$. El viajero es invisible en las comparativas localizadoras $(\$ 6)$ y en sintagmas preposicionales con movimiento ficticio ( $\$ 8-10)$.

Antes de entrar en materia, es oportuna una aclaración sobre la terminología que voy a emplear. En una relación espacial intervienen dos elementos: el elemento cuyo emplazamiento o desplazamiento se localiza en el espacio, y el elemento que permite localizarlo. Al primero lo llamaré Locatum; al segundo, Relatum ${ }^{2}$. En las situaciones estáticas ( sc. estados de reposo), no cabe más que una relación espacial de Ubicación. En las situaciones dinámicas ( $s c$. que implican un desplazamiento), pueden establecerse relaciones de Destino (o Dirección), Origen (o Procedencia) y/o Trayecto (o Recorrido).

\section{METONIMIA: VIAJEROS DE INCÓGNITO}

No es difícil encontrar ejemplos de movimiento ficticio en textos griegos antiguos. Aparecen en historiadores, en geógrafos y en otros muchos autores, pero también en inscripciones que carecen de pretensio-

\footnotetext{
${ }^{1}$ Quiero expresar mi gratitud a Joaquín Garrido Medina por las valiosas observaciones y sugerencias que me hizo sobre una versión anterior de este trabajo. En las citas griegas he optado por una traducción lo más pegada posible al texto griego en detrimento de la elegancia y de la naturalidad del español.

${ }^{2}$ Otras opciones serían Trajector y Landmark 'Trayector' y 'Punto de referencia' y Figure y Ground 'Figura' y 'Fondo', pero estos términos, pese a la popularidad de que gozan, son equívocos. Por un lado, resulta chocante hablar de trayectores en situaciones estáticas. Por otro, se da la paradoja de que una Figura puede estar situada detrás del Fondo: el jardín (Figura = Locatum) queda detrás de la casa $($ Fondo = Relatum $)$.
} 
nes literarias. No era, pues, una figura literaria, sino -como sucede entre nosotros- un recurso usado en la lengua corriente. En Heródoto, por ejemplo, encontramos un foso que corre alrededor de Babilonia (1a), un zigurat descrito como una serie de torres que están subidas unas encima de otras (1b) o cadenas de dunas (1c) y cordilleras (1d) que descienden y se extienden. Pese a las apariencias, (1e) es también un caso de movimiento ficticio, pues el «desplazamiento» no se refiere a los adirmáquidas, sino al territorio que ocupan:

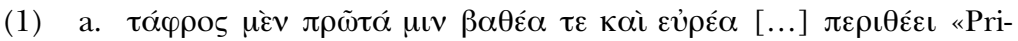
mero, un foso profundo y ancho la recorre alrededor» (Heródoto I 178.132).

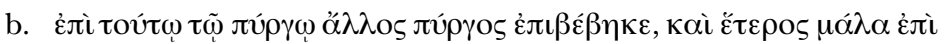

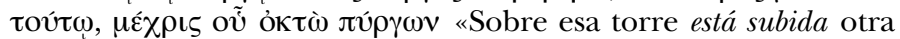
torre, y luego otra encima de esa hasta ocho torres» (Heródoto I 181.9).

c. ن்

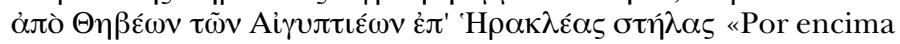
de la [Libia] infestada de fieras, desciende una ceja de arena que $s e$ extiende desde la Tebas egipcia hasta las columnas de Hércules» (Heródoto IV 181.3).

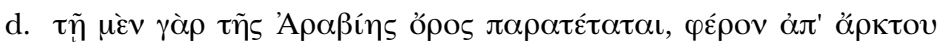

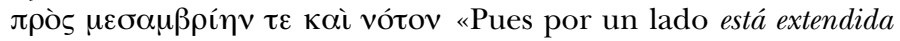
a modo de reborde la cordillera de Arabia, que lleva del norte al sur y suroeste» (Heródoto II 8.3).

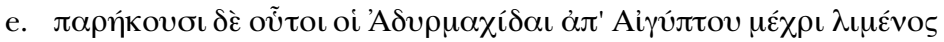

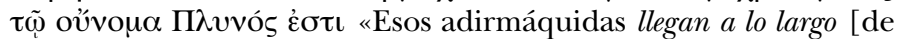
la costa] desde Egipto hasta un puerto cuyo nombre es Plino» (Heródoto IV 168.11).

Este tipo de movimiento ficticio con verbos dinámicos intransitivos es el que resulta más obvio'. Talmy lo denomina coverage path 'trayecto de superposición' (1996, p. 243) o coextension path 'trayecto de coextensión' (2000, p. 138) ${ }^{4}$ :

\footnotetext{
3 Cf. Schwyzer y Debrunner 1950, p. 459, quienes hablan de «dirección en el reposo» (Richtung in der Ruhelage) y también Jiménez Delgado 2008, pp. 148-149.

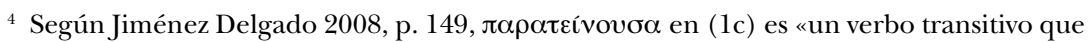
no expresa movimiento, sino la colocación de un paciente en el espacio por parte de un agente que se elimina de la representación» (¿una pasiva sin agente explícito?). En realidad, hay una acción intransitiva espontánea sin agente reconocible (anticausativa), tipo que en griego

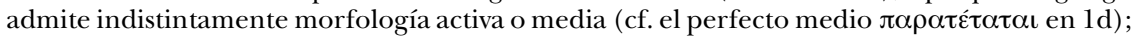
cf. esp. La veleta gira (frente a Juan se gira, reflexivo), pero La veleta se tuerce (pronominal anticausativo) o Juan (se) resbaló. Por lo demás, la expansión, sea radial, sea longitudinal como en (1c), es una variante de coextension path frecuente en las lenguas: ingl. The field spreads out in all directions from the granary «El campo se extiende en todas direcciones desde el granero», según el modelo de The oil spread out in all directions from where it spilled «El aceite se extendió en todas direcciones desde donde se derramó» (ejemplos de Talmy 2000, p. 138).
} 
A coextension path is a depiction of the form, orientation, or location of a spatially extended object in terms of a path over the object's extent. What is factive here is the representation of the object as stationary and the absence of any entity traversing the depicted path. What is fictive is the representation of some entity moving along or over the configuration of the object. Though it is not specified, the fictively moving entity can often be imagined as being an observer, or the focus of one's attention, or the object itself, depending on the particular sentence.

Dentro del mismo tipo, también es frecuente el uso de verbos transitivos. En griego los caminos y carreteras, los pasadizos, los desfiladeros o las cordilleras (2a-b) conducen o llevan a la gente a su destino a modo de cintas transportadoras. Como en español, con estos verbos queda sobrentendido un objeto directo, que por defecto se identifica con un referente genérico: cualquiera, la gente $e^{5}$. En la descripción del canal circular que rodea la mítica ciudad de Atlántide (2c), Platón atribuye el movimiento del agua al propio canal, como si tuviera capacidad motriz:

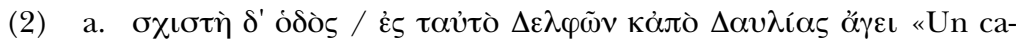
mino escindido conduce al mismo punto desde Delfos y Daulia» (Sófocles, Edipo rey 733-734).

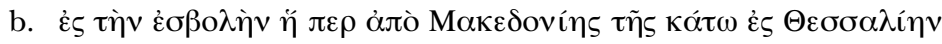

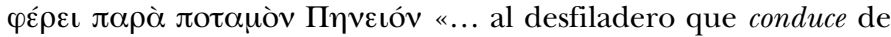
la Baja Macedonia a Tesalia a lo largo del río Peneo» (Heródoto VII 173.7).

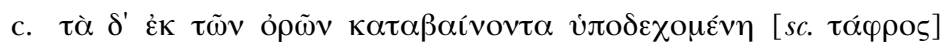

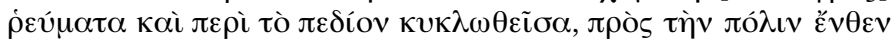

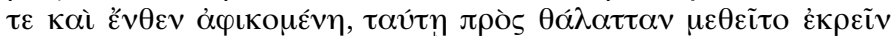
«[El foso], tras recibir los arroyos que bajaban de los montes y tras circular en torno a la llanura, al llegar a la ciudad desde un lado y de otro, por allí echaba el agua y dejaba que corriese al mar» (Platón, Critias 118d).

Curiosamente, óyvı 'calle' en Homero es el femenino de un tipo arcaico del participio de perfecto del verbo ó $\gamma \omega$ : 'que tiene conducido'. También $\lambda \varepsilon \omega \varphi o ́ \rho o \varsigma ~ ' c a r r e t e r a '$ es un adjetivo compuesto de $\lambda \varepsilon \omega ́ \varsigma$ 'gente' y $\varphi \varepsilon ́ \rho \omega$ 'llevar' '.

En el mundo real, ninguna de las entidades que figuran en (1) y (2) tiene la capacidad de desplazar(se). Son entidades estáticas, preferentemente de configuración longitudinal, y corresponden a un Trayecto que puede recorrer una persona. Por metonimia, el movimiento de esa

${ }^{5}$ Martínez Vázquez 2008, pp. 97-99, ve aquí «una construcción, intransitiva, como en castellano». Sin embargo, en enunciados no genéricos, la aparición de un objeto directo explícito es perfectamente normal (véase el ejemplo 34f).

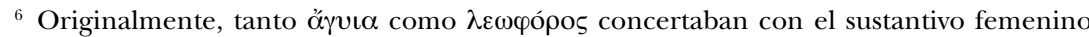
ódós ‘camino', que quedaba sobrentendido. 
persona se transfiere a la entidad inmóvil. Como consecuencia, lo que en principio es un Relatum con función de Trayecto (3a), sobre el modelo de entidades inanimadas móviles como las de (3b-c), se promueve a la función de Locatum móvil (3d) ${ }^{7}$.

(3) a. El caminante va a Atenas por el camino.

b. El río va / lleva a Atenas.

c. El fuego avanza hacia Atenas.

d. El camino va / lleva a Atenas.

El movimiento ficticio es una manifestación más del antropocentrismo con que los seres humanos concebimos y percibimos a nuestra imagen y semejanza el mundo que nos rodea, atribuyendo rasgos y cualidades humanas a entidades que sabemos inanimadas. En griego, los ríos entregan sus aguas a otro río (4a) -también nosotros hablamos de ríos tributarios- y reciben a sus afluentes $(3 \mathrm{~d}, 4 \mathrm{~b})$, pero además se dice que una región recibe de otra con el sentido de que «viene a continuación» (4c). Como en español, las casas griegas miran a los distintos puntos cardinales $(4 d)$ :

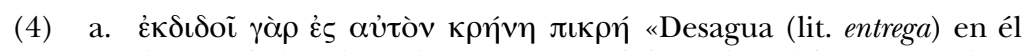
(sc. en el río Hípanis) una fuente salobre» (Heródoto IV 52.8).

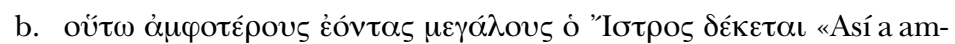
bos [ríos] cuando ya son caudalosos, los recibe el Istro" (Heródoto IV 41.3).

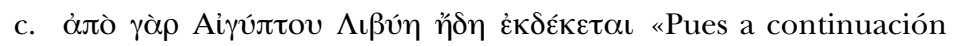
de Egipto ya viene Libia [lit. de Egipto recibe Libia]» (Heródoto IV 41.3).

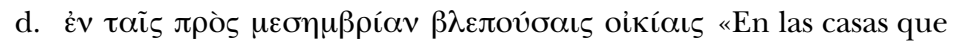
miran a mediodía» (Jenofonte, Memorias de Sócrates III 8.9).

\section{DAtivo De PUnTo DE VISTA: VIAJEROS Discretos}

El «viajero imaginario» que presuponen las descripciones topográficas con movimiento ficticio de la sección 3, se manifiesta a menudo de forma más explícita. Es frecuente el uso del llamado «dativo de punto de vista» (o dativus iudicantis). Este dativo expresa una persona, un Observador, desde cuyo punto de vista resulta cierto el contenido de una oración. En el caso del movimiento ficticio, aparece un participio en dativo que remite a una persona inespecífica que se desplaza. En este

\footnotetext{
7 Martínez Vázquez 2008, pp. 98-99, propone como interpretación alternativa que la ruta entendida como medio desplaza al agente con un sentido «facilitativo», pero esta explicación, innecesariamente complicada, no se aviene bien con otras manifestaciones del movimiento ficticio.
} 
caso, el viajero es puramente virtual, pero el movimiento es verídico. En

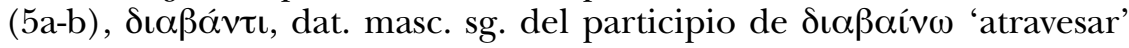
(lit. para uno que ha atravesado), se combina con situaciones de movimiento ficticio. En (5c-d) los participios en dativo $\dot{\varepsilon} \sigma \pi \lambda \varepsilon \dot{\sigma} \sigma \tau \tau \iota$ ( $\dot{\varepsilon} \sigma \pi \lambda \varepsilon \dot{\varepsilon} \omega$

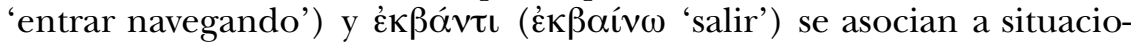
nes estáticas:

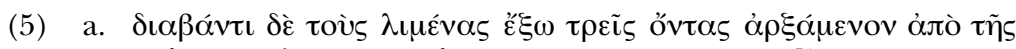

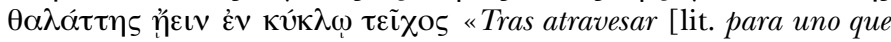
había atravesado] los puertos exteriores, que eran tres, iba en círculo una muralla que arrancaba del mar» (Platón, Critias 117e).

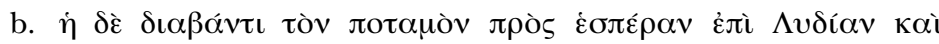

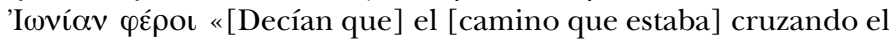
río hacia el oeste, llevaba hasta Lidia y Jonia» (Jenofonte, Anábasis III 5.15).

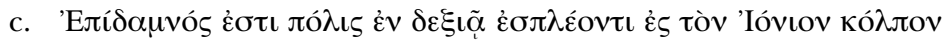
«Epidamno es una ciudad a la derecha entrando por mar (lit. para uno que entra por mar) en el golfo Jónico» (Tucídides I 24.1).

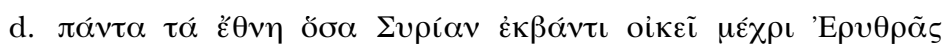

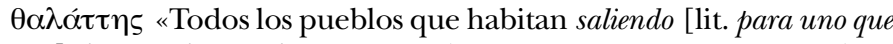
sale] de Siria hasta el mar Rojo» (Jenofonte, Ciropedia VIII 6.20).

El dativo de punto de vista puede aparecer también en plural:

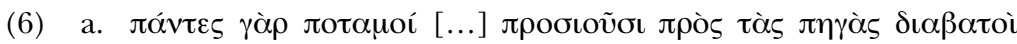

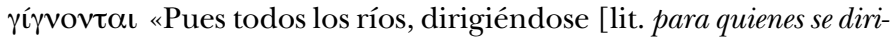
gen] a las fuentes, se vuelven vadeables» (Jenofonte, Anábasis III 2.22).

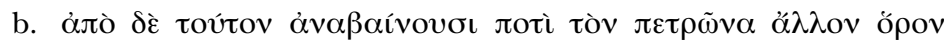

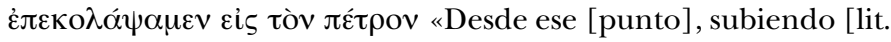
para quienes suben] hacia el peñascal, grabamos otra marca de límite en la peña» (Decisión de unos árbitros rodios en un conflicto territorial entre Priene y Samos, IPriene XXXVII 166.167, s. II a.C. $)^{8}$.

Como opción alternativa, se emplea el genitivo de punto de vista ( siempre en plural), muy raro en época clásica (7a) y más común en época helenística e imperial $(7 \mathrm{~b}-\mathrm{c})$ :

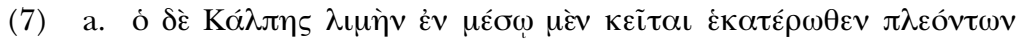

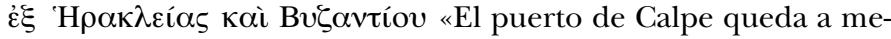
dio camino de cada uno de los dos puntos, saliendo por mar [lit. de los que salen por mar] de Heraclea y Bizancio» (Jenofonte, Anábasis VI 4.1).

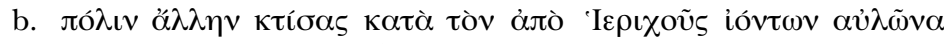

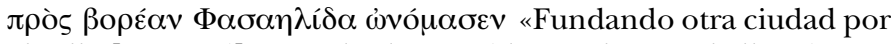
el valle [que está] yendo desde Jericó hacia el norte, la llamó Faselis» (Josefo, Sobre la guerra de los judios I 418.4).

\footnotetext{
${ }^{8}$ De la sintaxis de $\alpha \dot{v} \alpha \beta \alpha i ́ v o v \sigma ı$ en este ejemplo se tratará más abajo.
} 


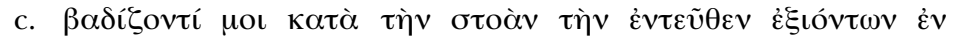

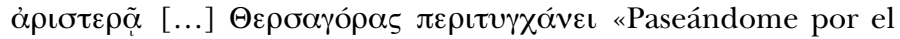
pórtico [que está] saliendo de allí a la izquierda [lit. a la izquierda de los que salen], Terságoras se encuentra conmigo» (Ps.-Luciano, Elogio de Demóstenes I 1).

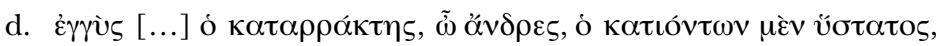

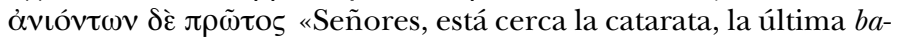
jando [el Nilo] y la primera remontándolo» (Filóstrato, Vida de Apolonio de Tiana VI 26.6).

Originalmente, este genitivo tenía carácter posesivo y estaba regido por un sustantivo $(7 \mathrm{a}, 7 \mathrm{c})$, pero acabó por adquirir autonomía sintáctica $(7 b, 7 d)$.

Estas tres construcciones son equivalentes, tanto que en su guía de Grecia Pausanias (s. II d.C.) puede coordinarlas con entera libertad:

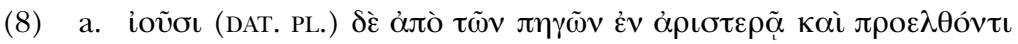

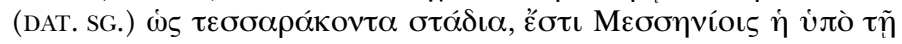

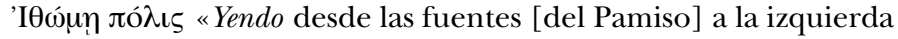
y avanzando unos 40 estadios, está la capital de los Mesenios de al pie del Itome» (Pausanias IV 31.4).

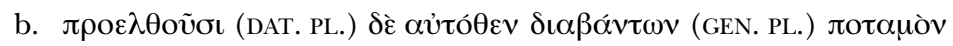

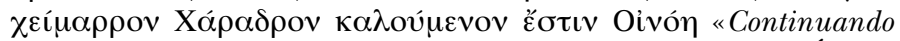
desde allí y cruzando el torrente llamado Barranco, está Énoe» (Pausanias II 25.2).

Como sugieren las traducciones, estos participios en dativo o genitivo son funcionalmente equiparables al «gerundio locativo» del español en (9) (Fernández Lagunilla 1999, p. 3484):

(9) Hay un bar bajando la calle.

Conviene puntualizar que el valor de este gerundio es «localizador» más que propiamente «locativo», pues no describe directamente la Ubicación del Locatum, sino un Trayecto para llegar hasta él. Este tipo de movimiento ficticio es el que Talmy 1996, 2000 denomina access path 'trayecto de acceso':

An access path is a depiction of a stationary object's location in terms of a path that some other entity might follow to the point of encounter with the object. What is factive here is the representation of the object as stationary, without any entity traversing the depicted path. What is fictive is the representation of some entity traversing the depicted path, whether this plausible or implausible. Though it is not specified, the fictively moving entity can often be imagined as being a person, some body part of a person, or the focus of one's attention, depending on the particular sentence (Talmy 2000, p. 136) 
Hay una diferencia esencial entre la sintaxis de los participios del griego y el gerundio del español. El español no establece diferencia formal entre el gerundio de (9) (movimiento ficticio) y el de (10) (movimiento real):

(10) Encontré un bar bajando la calle.

Del contexto oracional deducimos que en (10) el sujeto del gerundio coincide con el del verbo principal. No sucede lo mismo en (9), donde «la acción se predica de un sujeto inespecífico, bajo el que se oculta el emisor o el receptor» (Fernández Lagunilla 1999, p. 3484). En otras palabras, hay un argumento vacío, que, por defecto, se completa con un referente genérico.

En griego la sintaxis del participio es distinta. En $(11 \mathrm{a}=5)$, el participio en dativo se refiere a un participante (Observador) externo al núcleo del predicado. Por el contrario, en (11b) el participio concuerda con uno de los argumentos nucleares, el sujeto en este caso:

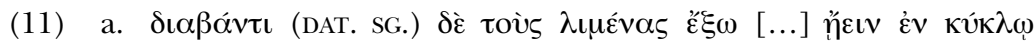
$\tau \varepsilon \tilde{\chi} \chi 0 \varsigma$ «Para uno que había atravesado los puertos exteriores $i b a$ en círculo una muralla» (Platón, Critias $117 \mathrm{e}$ ).

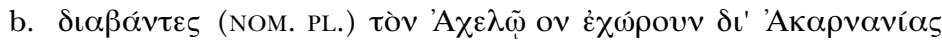
«Tras cruzar el Aqueloo, fueron avanzando por Acarnania» (Tucídides III 106.1).

A este respecto llama la atención la discordancia sintáctica que se aprecia en el ejemplo (6b) que vimos más arriba. Los árbitros rodios narran en $1^{a}$ persona ( $\dot{\pi} \varepsilon \kappa \kappa \lambda \alpha ́ \alpha \psi \alpha \mu \varepsilon v$ 'inscribimos') cómo han recorrido el terreno para marcar las lindes. A priori, esperaríamos óv $\alpha \beta \alpha i ́ v o v \tau \varepsilon \varsigma . .$.

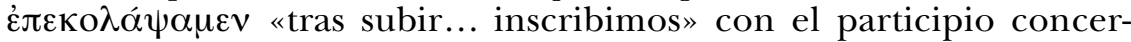
tando con el sujeto en nominativo plural. En realidad, el participio óv $\alpha \beta \alpha i ́ v o v \sigma \iota$ (dat. pl.) no remite al movimiento real de los árbitros, sino al movimiento virtual de unos «viajeros imaginarios» que intentan localizar (mentalmente) el peñascal ${ }^{9}$.

Otros ejemplos de discordancia son los siguientes ${ }^{10}$ :

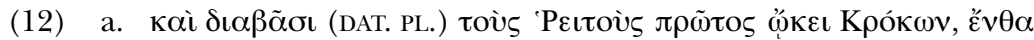

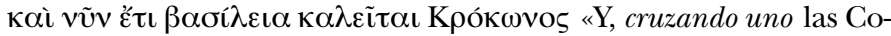
rrientes, Crocón fue el primero que estuvo viviendo en el lugar que aún se llama Palacio de Crocón» (Pausanias I 38.2).

\footnotetext{
${ }^{9}$ Los casos de (5a) y (5b) son distintos, pues ni la muralla cruza los puertos, ni el camino cruza el río. Para un participio concertado en contexto de movimiento ficticio sensu stricto veáse el ejemplo (36b).

${ }^{10}$ Las traducciones pretenden reflejar la incoherencia sintáctica del griego. Para discordancias con la $2^{\underline{a}}$ persona genérica, véase $\$ 5$.
} 


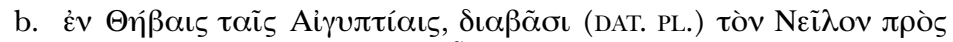

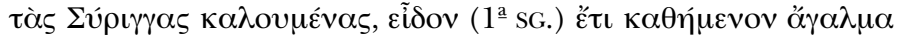

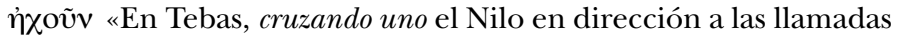
Siringes, aún vi una estatua sedente que emitía sonidos» (Pausanias I 42.3).

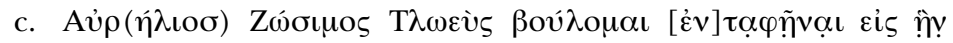

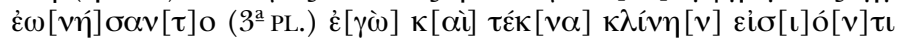

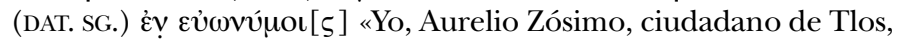
deseo ser enterrado en el nicho que compraron ( entrando uno a la izquierda» (TAM II 619.1-7; Tlos, Licia occidental, época romana).

La discordancia es sólo aparente. Los participios $\delta \iota \alpha \beta \tilde{\alpha} \sigma \iota$ (12a-b)

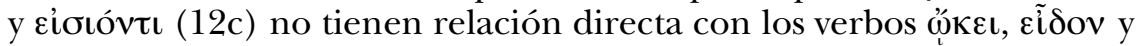

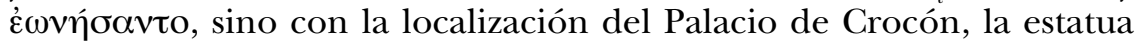
sonora y el nicho funerario.

Es posible que estas anomalías reflejen una fase embrionaria de la lenta metamorfosis que transformó los antiguos participios flexivos en el gerundio invariable del griego moderno ${ }^{11}$. Este admite un uso localizador análogo al del español como se comprueba en el siguiente ejemplo de Pausanias (13a) y su traducción al griego moderno (13b):

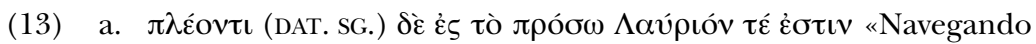
hacia adelante, está Laurion» (Pausanias I 1.1).

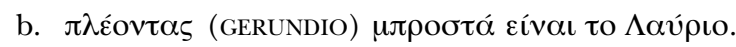

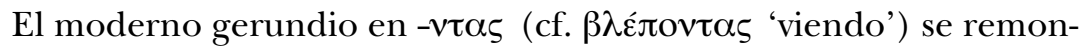

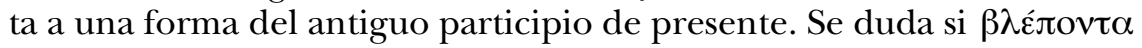
era el acusativo masculino singular o el nominativo-acusativo neutro plural, formas accidentalmente homófonas. La primera opción parece preferible (Méndez Dosuna 2000, pp. 289-290). El gerundio de aoristo

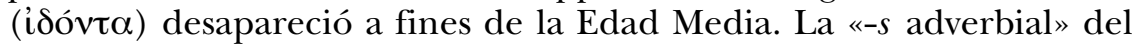

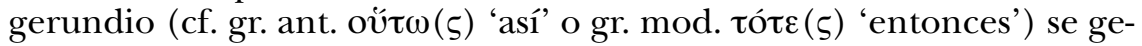
neralizó a finales del periodo bizantino y no en todos los dialectos.

Los dativos y genitivos «discordantes» del griego clásico tienen apariencia de participios, pero se comportan ya como gerundios. La sintaxis toma la delantera a la morfología, que tardará algunos siglos en despojarse de oropeles flexivos.

\footnotetext{
11 Para los participios invariables y el gerundio, cf. Mirambel 1961; Mandilaras 1973, pp. 352-370; Langholf 1977a, pp. 61-70, 1977b; Petersmann 1979; Brixhe 1987, pp. 86-87; Horrocks 1997, p. 180; Tsimpli 2000.
} 


\section{LA $2^{\underline{a}}$ PERSONA GENÉRICA: VIAJEROS APARENTES}

El viajero imaginario puede asumir otros papeles sintácticos que le confieren mayor «visibilidad». Así, es frecuente la $2^{a}$ persona genérica como sujeto de un verbo en futuro a modo de indicaciones para llegar a un destino:

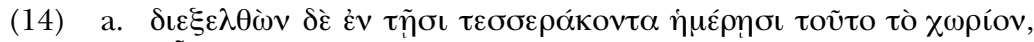

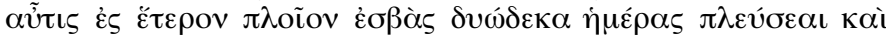

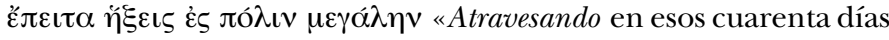
ese territorio y embarcando de nuevo en otro barco navegarás doce días y luego llegarás a una gran ciudad» (Heródoto II 29.18).

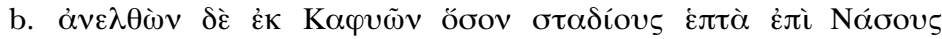

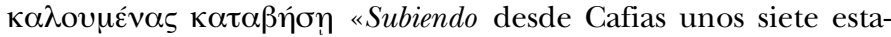
dios, bajarás a las llamadas Nasoi (Islas)» (Pausanias VIII 23.8).

En Pausanias no son raros los participios discordantes en dativo y genitivo combinados con una $2^{\underline{a}}$ persona genérica:

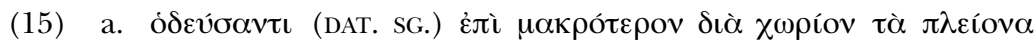

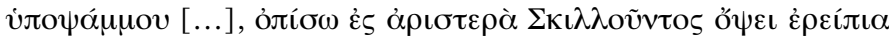
«Caminando uno un rato bastante largo por un terreno en su mayor parte medio arenoso, luego a la izquierda verás las ruinas de Escilunte» (Pausanias V 6.4).

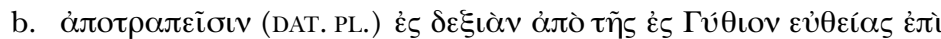

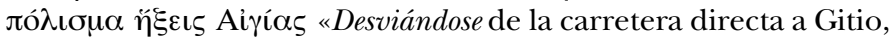
llegarás a la ciudad de Egias» (Pausanias III 21.5).

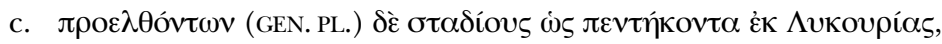

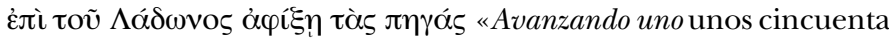
estadios desde Licuria, llegarás a las fuentes del Ladón» (Pausanias VIII 20.1).

Hay aquí un híbrido de las construcciones de (14) con las de (5-7). Seguramente el hecho de que los dativos y genitivos de punto de vista compartan con la $2^{\underline{a}}$ persona una referencia genérica favorecía su combinación ${ }^{12}$.

La $2^{\underline{a}}$ persona puede aparecer también como Objeto Directo al que recibirá un lugar. Aquí el antropomorfismo da un paso más, pues la acción de recibir (gr. $\delta \varepsilon ́ \chi o \mu \alpha l$, con numerosos compuestos) es propia de un sujeto humano.

En época clásica hay puertos o tumbas concebidos como lugares de $\operatorname{acogid}^{13}$ :

${ }^{12}$ Nótese que, a diferencia de los ejemplos analizados en la sección anterior, aquí los participios denotan inequívocamente acciones del sujeto.

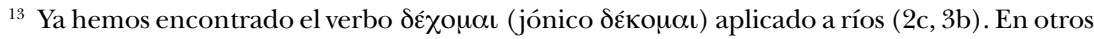

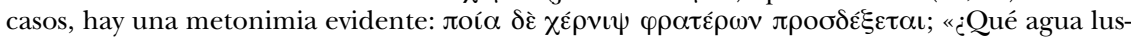
tral de unos miembros de fratría recibirá [a Orestes]?» (sc. "¿Qué fratría lo recibirá y compartirá su agua lustral con él?») (Esquilo, Euménides 656). 


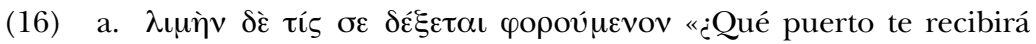
transportado [así]?» (Aristófanes, La paz 144).

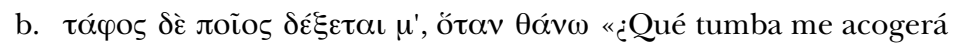
cuando muera?» (Eurípides, Ifigenia entre los tauros 625).

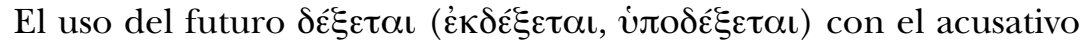
de la $2^{\underline{a}}$ persona es un manierismo que Pausanias emplea reiteradamente en los tres últimos libros de su Periégesis (ocho ejemplos) en referencia a llanuras, ríos, bosques, montes y comarcas que no parecen especialmente acogedores:

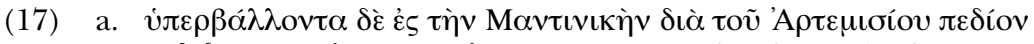

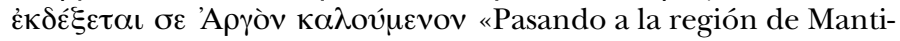
nea por el templo de Artemis, te recibirá una llanura llamada Erial» (Pausanias VIII 7.1).

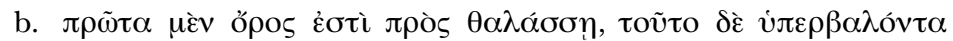

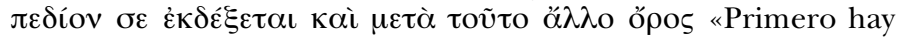
un monte junto al mar y, sobrepasándolo, te recibirá un llano y tras él otro monte» (Pausanias IX 32.2).

Dos autores tardíos, Elio Aristides (s. II d.C.) y Claudio Eliano (ss. II-III d.C.), rizan el rizo en el proceso de transferencia metonímica al invertir la perspectiva del viajero y su entorno:

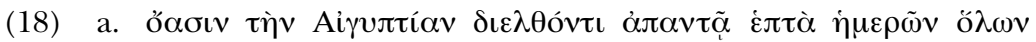

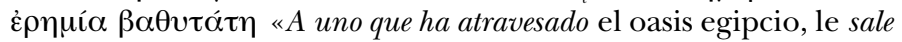
al paso un profundísimo desierto de siete días completos» (Eliano, Sobre la naturaleza de los animales X 25.1).

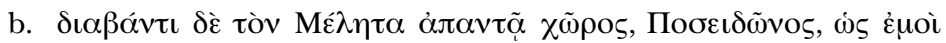

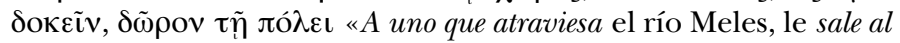
paso un lugar, regalo -a mi parecer- de Poseidón para la ciudad» (Elio Arístides, Discurso político sobre Esmirna CCXXXIII 25 Jebb).

El viajero, que es quien realmente se desplaza, aparece quieto y es el entorno inmóvil el que se presenta como si avanzara a su encuentro. Talmy 1996, 2000, define así este «estatismo ficticio», que él denomina observer-based frame-relative motion 'movimiento relativo del marco basado en el observador':

A form of fictive motion, $[\ldots]$ in which the factively stationary surroundings are fictively depicted as moving. In a complementary fashion, [...] the factively moving observer is now fictively depicted as stationary (Talmy 1996, p. $238=2000$, p. 130). 


\section{ORACIONES COMPARATIVAS LOCALIZADORAS}

Analicemos ahora un tipo curioso de oraciones introducidas por $\dot{\omega} \varsigma$ 'como, igual que, según' o, con menor frecuencia, por sus sinónimos  ticio $(20 \mathrm{a}-\mathrm{b})$ :

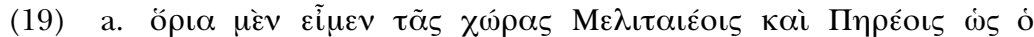

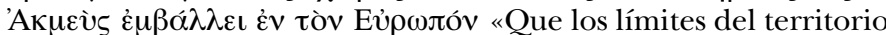
para los de Melitea y los de Perea estén según desemboca el Acmeo en el Europo» (Sinecismo de Melitea y Perea auspiciado por la Confederación Etolia, IG IX(2) 205.3-5, Melitea, post a. 212 a. C.).

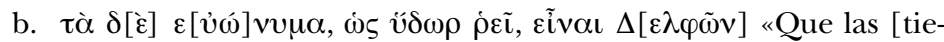
rras] de la izquierda según corre el agua, sean de Delfos» (Delimitación de fronteras entre Delfos y Ambriso-Fligonio, FD III(2) 136.18-20, Delfos, ca. 140 a.C.) .

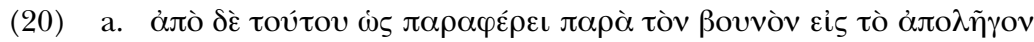

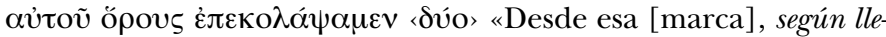
va [el camino] por el borde el monte hasta el final de este, inscribimos dos marcas» (Decisión de unos árbitros rodios en un conflicto territorial entre Priene y Samos, IPriene XXXVII 167.168, s. II a.C.).

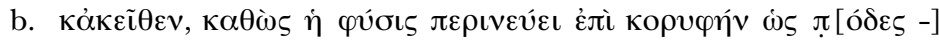
«Y desde allí, según se va inclinando la naturaleza del terreno hasta la cumbre, [la distancia es de] unos ... pies» (IG V(1) 1431.35-36, Mesene, 78 d.C.).

Estas oraciones son comparables a giros del español como los de (21) que, a su vez, equivalen a la construcción con gerundio de (10):

(21) a. Hay un bar según se baja la calle (impersonal).

b. Hay un bar según uno baja la calle (indefinido inespecífico).

c. Hay un bar según bajas la calle (2 $2^{a}$ persona genérica).

d. Hay un bar según bajo la calle (1 $1^{a}$ persona genérica).

e. Hay un bar según baja la calle (movimiento ficticio).

En griego, con la excepción de un par de testimonios en Teócrito (29), no se atestiguan oraciones con ws localizador en los textos literarios, quizá porque se percibían como demasiado coloquiales. Tampoco hay nada parecido a las comparativas del español de (21), ni siquiera en las inscripciones.

Este tipo de oraciones ha sido poco estudiado en griego. Los diccionarios y las gramáticas atribuyen a ós un valor «locativo» supuestamente dialectal, sc. extraño al ático y a la koiné. Así, el diccionario de Liddell y Scott, s.v. ws Ae, registra una acepción «Local, where, in dialects». En realidad, ni existe un w̧s locativo, ni el uso es dialectal (Méndez Dosuna 1999a). 
No parece tampoco que en español las oraciones del tipo ejemplificado en (21) hayan despertado excesiva curiosidad. Prueba de ello es que no aparecen en la gramática de Bosque y Demonte 1999.

La primera pregunta que surge es cuál es la naturaleza de estas oraciones, pues tanto gr. ant. ẇs como esp. según (Pavón Lucero 1999, p. 589, de Bruyne 1999, p. 697) admiten una lectura temporal. Así, en español (22a) y (22b) son oraciones más o menos equivalentes:

(22) a. Hay un bar según tuerce la calle.

b. Hay un bar cuando tuerce la calle.

Sin embargo, la equivalencia es engañosa. En (23a) el bar está en algún punto de la cuesta (baja se interpreta como durativo), mientras que en (23b) se entiende que el bar está al comienzo de la cuesta (baja se interpreta como inceptivo). La hipotética versión (23c) es absurda. Tampoco es posible convertir (24a) en (24b):

(23) a. Hay un bar según baja la calle.

b. Hay un bar cuando baja la calle.

c. *Hay un bar a medida que baja la calle.

(24) a. La linde del terreno va según indican los mojones.

b. *La linde del terreno va cuando indican los mojones.

El valor comparativo de $\mathfrak{\omega} s$ queda más claro en griego, donde puede aparecer $\dddot{\sigma} \pi \varepsilon \rho$ (cf. 28c), que no admite lectura temporal. También en un pasaje del fuero de Oreja (hoy Colmenar de Oreja, Madrid), fechado en 1139 (apud Ménendez Pidal 1911, s.v. Alcarias), aparecen giros inequívocamente comparativos: quomodo en la versión latina (25a) y así como en la romance (25b), que equivalen a según en el uso actual (25c):

(25) a. Inde uero ad montem de Alcarrias quomodo descendit Taiunna in Saramba.

b. E dende fasta dentro en las Alcarrias así commo descende Tajuña en Jarama.

c. Y desde alli hasta la Alcarria según baja el Tajuña al Jarama.

En este tipo de comparativas se establece un paralelo con un Trayecto que permite ubicar -mentalmente- un Locatum: según baja la calle = por donde baja la calle. Las oraciones introducidas por $\tilde{\alpha} \mathrm{l}$ "por donde' (jón.-át. ĩı) en textos en dialecto dórico de (26) tienen un sentido análogo a las de (20):

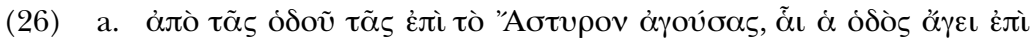

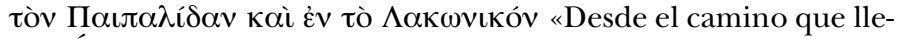
va a Ástiro, por donde el camino lleva hasta la cima del Pepálida y al Lacónico» (reglamento de pastos, SIG DCXXXVI 22-24, Delfos, ca. 178 a.C.) . 


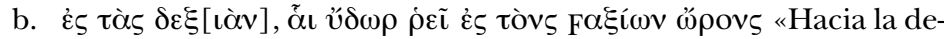
recha, por donde corre el agua hasta los límites con Axo» (IC IV 174.10-11, Gortina, Creta, ca. 165 a. C.) .

Un fragmento de una inscripción, en que se consignan distintos contratos de compra-venta de terrenos ilustra bien este aspecto del movimiento ficticio:

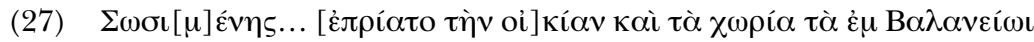

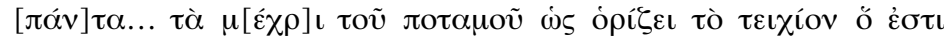

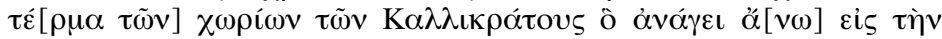

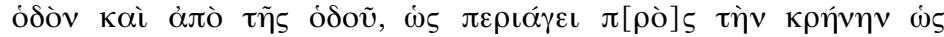

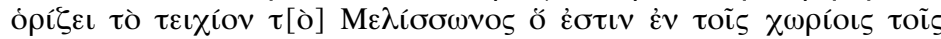

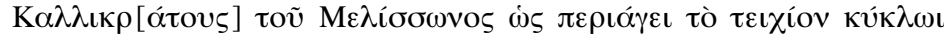

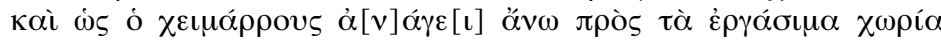

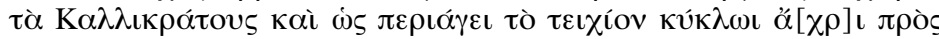

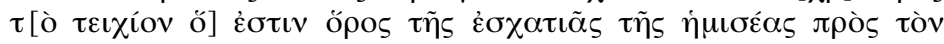

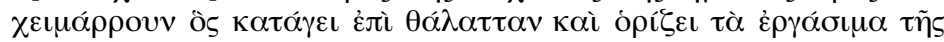

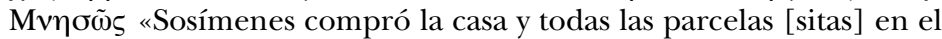
Baño, las [que llegan] hasta el río según delimita el murete que es el límite de los terrenos de Calícrates y que lleva arriba al camino, y desde el camino según lleva rodeando en dirección a la fuente, según delimita el murete de Melisón que está entre las parcelas de Calícrates y Melisón según lleva rodeando el murete en círculo y según lleva arriba el torrente en dirección a las tierras de labor de Calícrates y según lleva rodeando en círculo el murete hasta el murete que es el límite de la mitad de la finca en dirección al torrente que conduce al mar y delimita las tierras de labor de Mnesó»(IG XII 5.872-78ss., Tenos, s. III a.C.).

El redactor del texto dota ficticiamente de movimiento a ciertos elementos que delimitan la propiedad. De los dos torrentes que se mencionan, el segundo «lleva abajo» conforme al orden natural de las cosas. El segundo, en cambio, «lleva hacia arriba». Este movimiento contrario a la gravedad es imposible en una corriente de agua. Es obvio que el redactor piensa en alguien que recorre los límites de la propiedad a pie (recorrido real), con la mirada (recorrido visual) o con la imaginación (recorrido mental). Se trata, pues, de cauces secos (torrenteras) más que de corrientes de agua (torrentes).

Un hecho aún más llamativo es que en griego -como en español- las comparativas localizadoras admiten verbos estáticos, que a priori deberían ser refractarios a la idea de desplazamiento:

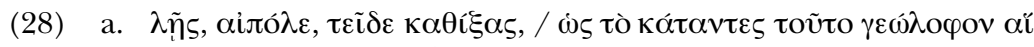

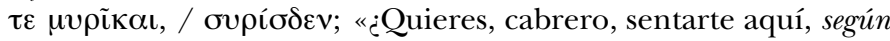
[están] esa colina empinada y los tarajes, a tocar la siringe?» (Teócrito I 12.14).

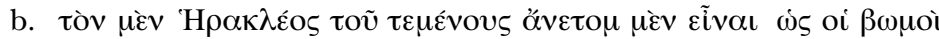

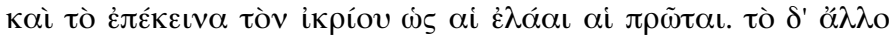

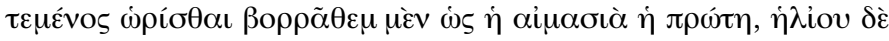




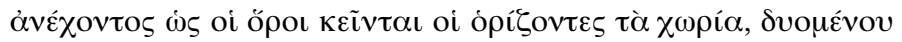

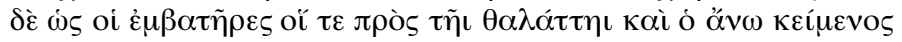
«Que del recinto sagrado de Heracles esté despejado [lo que queda] según [están] los altares y lo de más allá del entablado según [están] los primeros olivos. Que el resto del recinto quede delimitado por el norte según [está] la primera tapia; por el este, según están situados los mojones que delimitan las parcelas; por el oeste, según están los accesos (?) de junto al mar y el que está situado arriba» (Ath. Agora XIX L 4b.8-17; Atenas, ¿ca. 265/264 o 251/250?).

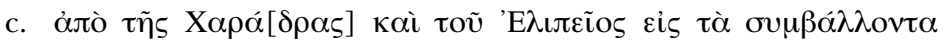

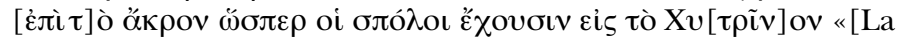
frontera va] desde la Torrentera y el Elipeo hasta la confluencia y hasta la cumbre tal como están puestas las estacas hasta el Quítrino» (FD IV 351.27-30; Delfos, ca. 250 a.C.).

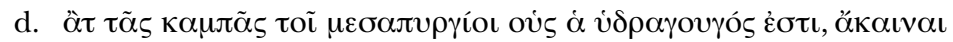

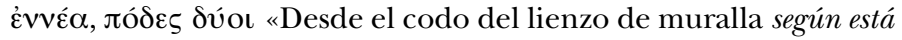
el canal de agua, [hay] nueve pértigas y dos pies» SEG XLIII.311.B51 (Escotusa, Tesalia, ca. 197-185 a.C. $)^{14}$.

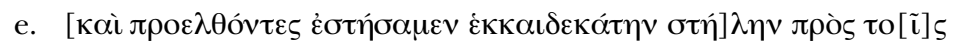

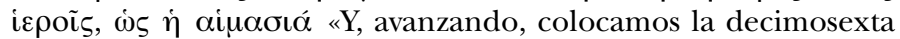
lápida junto a los [terrenos] sagrados según [está] la tapia» (Revisión de los límites del témenos de Ártemis, IEph. MDXXV 2.3, Éfeso, 27 a. C.-14 d.C.).

En todos estos casos, la comparativa localizadora contiene un movimiento ficticio encubierto. Los Relata longitudinales (un muro, un camino, una línea de altares, de olivos, de mojones o de estacas) que forman un trayecto y la oración principal, en la que hay un movimiento real (28e) o ficticio (28b-d), activan la idea de recorrido en la oración comparativa.

Aunque menos frecuentes, también hay comparativas localizadoras con Relata no longitudinales:

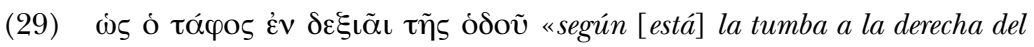
camino» (Didyma 492c.65-67; Dídima, ca. 254/253 a. C.) .

Aquí la comparativa equivale a un Trayecto que pasa cerca del sujeto: según está situada la tumba = por donde está la tumba.

\section{AlgunAS PECUliaridAdeS DEL MOVIMIENTO FICTICIO}

En esta sección comentaré sucintamente algunas de las características del movimiento ficticio que Matsumoto 1996 identificó en inglés y en japonés.

\footnotetext{
${ }^{14}$ Oưs [hōs] es variante fonética de $\dot{\omega} \varsigma$ [hōs] con el cierre de las vocales medias largas característico del dialecto tesalio.
} 
En primer lugar, la «direccionalidad» de los elementos estáticos dotados ficticiamente de movimiento se mantiene incluso en sintagmas nominales en los que no hay un verbo dinámico explícito:

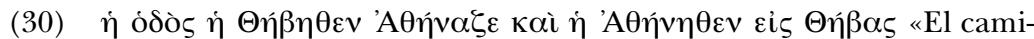
no de Tebas a Atenas y el de Atenas a Tebas» (Aristóteles, Física 202b, Bekker).

Las oraciones con movimiento ficticio admiten fácilmente modificadores referidos a la configuración del Trayecto (33a), pero no a otras circunstancias (velocidad, actitud) propias del movimiento real (33b-d) ${ }^{15}$. Como muestra la comparación con los ejemplos de (31-32) en español, el movimiento ficticio tiene características propias y no resulta de una transposición mecánica de los esquemas del movimiento real:

(31) a. El arroyo avanza sinuoso por el valle.

b. El arroyo serpentea perezoso por el valle.

c. El arroyo avanza veloz por el valle.

d. *El arroyo llega extenuado al valle.

(32) a. *El excursionista avanza sinuoso por el valle.

b. ${ }^{*}$ El excursionista serpentea perezoso por el valle.

c. El excursionista avanza veloz por el valle.

d. El excursionista llega extenuado al valle.

(33) a. El sendero avanza sinuoso por el valle.

b. ?El sendero serpentea perezoso por el valle.

c. ??El sendero avanza veloz por el valle

d. *El sendero llega extenuado al valle.

Por lo que se refiere al tiempo verbal, en una abrumadora mayoría de los ejemplos de movimiento ficticio, el verbo aparece en presente. Sin embargo, en ese presente el Tiempo no es lo importante. Lo que de verdad cuenta es el Aspecto. Se trata de presentes habituales, que indican que el Trayecto en cuestión está siempre en disposición de ser recorrido. Por lo demás, como es natural, el presente, aunque mayoritario, no es obligatorio. Cuando la descripción se sitúa en el pasado, se emplea el imperfecto (11a, 34a). Por la misma razón, en el «optativo oblicuo» ${ }^{16}$, sólo son posibles las formas del tema de presente, que tiene aspecto durati-

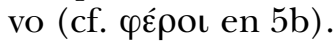

${ }^{15}$ Sí es posible, en cambio, el uso de verbos que expresan velocidad: La cordillera corre de norte a sur. También en griego se usa $\theta \varepsilon \dot{\omega} \omega$ 'correr' para el movimiento ficticio (36b). Los ejemplos (33c) y (33d) son aceptables en registros «poéticos».

${ }^{16} \mathrm{El}$ «optativo oblicuo» es un antiguo «mediativo» (ingl. evidential) degradado a simple marca de discurso indirecto, que no tiene nada que ver con la consecutio temporum del discurso indirecto del español (Méndez Dosuna 1999b). 
También en español se usan el presente y el imperfecto en enunciados genéricos $(34 \mathrm{a}-\mathrm{b})$. El pretérito indefinido es posible si el contexto implica una cierta duración (34c-d), pero no si remite a un pasado puntual (34e). También es perfectamente admisible con referentes no genéricos (34f).

(34) a. La carretera va a Madrid.

b. La carretera iba a Madrid.

c. ?Esta carretera fue a Madrid durante cien años.

d. ??Esta carretera estuvo yendo a Madrid durante cien años.

e. *Ayer esta carretera fue a Madrid.

f. Una romántica vereda condujo a los enamorados hasta el hotel.

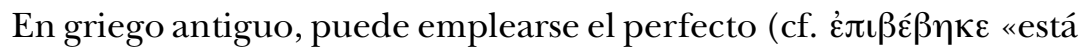
subida» en 1b), que tiene aspecto resultativo o el pluscuamperfecto, que es un resultativo de pasado.

Las lenguas imponen restricciones léxicas más o menos severas en el uso del movimiento ficticio. Matsumoto 1996 señala que en japonés la conversión de un Trayecto en Locatum dotado de movimiento ficticio sólo es posible con trayectos que una persona puede recorrer de manera efectiva (Matsumoto habla de travelability 'recorribilidad'): aparentemente, no es admisible una oración como (33) porque, en circunstancias normales, las personas no recorremos las líneas de alta tensión.

(35) Los cables de alta tensión cruzan el prado.

El griego clásico -como el inglés o el español-, es más permisivo. Por ejemplo, los muros pueden «llevar» a un lugar pese a que los muros en la vida real no son fácilmente recorribles. Aquí la «recorribilidad» tiene una base visual o mental:

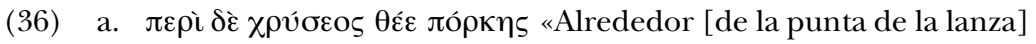
corría una abrazadera de oro» (Ilíada VI 320)

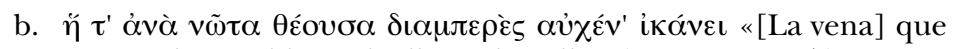
corriendo espalda arriba llega al cuello» (Iliada XIII 547).

Un humano no puede desplazarse por una abrazadera o una vena ${ }^{17}$. Aristófanes, el más ilustre representante de la comedia ateniense del siglo v a.C., anticipándose al «Teatro del absurdo» de mediados del siglo $\mathrm{XX}$, hace que Pistetero, uno los protagonistas de Las aves, proponga a su compañero Evélpides una ronda de vigilancia por el reborde de una olla. Un Trayecto que pertenece a la esfera del movimiento ficticio, se presenta como real:

17 Cf. Jiménez Delgado 2008, p. 149, n. 214, a propósito de (36b). 


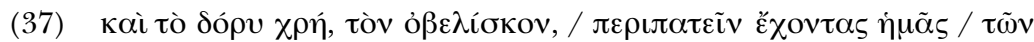

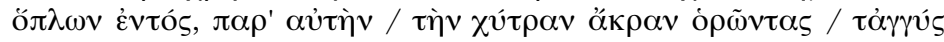
«Y tenemos que hacer la ronda portando la lanza -o sea, el asadordentro de la plaza de armas por el propio reborde de la olla mirando los alrededores» (Aristófanes, Aves 388-392).

\section{Acusativo y Dativo en SINTAGMas PREposicionales}

La sección 10 tratará del movimiento ficticio en los sintagmas preposicionales del griego antiguo. Para entender el problema que allí se planteará, es necesario tener una idea general de cómo funcionan las preposiciones y los casos en esa lengua ${ }^{18}$.

En principio, la Relación espacial es función del caso morfológico: el dativo expresa Ubicación, el genitivo expresa Procedencia y el acusativo expresa Destino o Trayecto. El uso espacial de los casos sin el apoyo de una preposición es normal en Homero y se mantiene como rasgo de la lengua de la poesía, pero en la prosa clásica está restringido a unos pocos topónimos y sustantivos referidos a lugares:

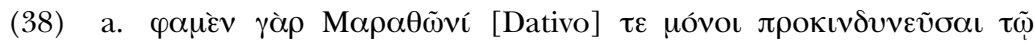
$\beta \alpha \rho \beta \alpha \rho_{i}$ «Pues afirmamos que en Maratón nosotros solos nos arriesgamos frente al bárbaro» (Tucídides I 73.4).

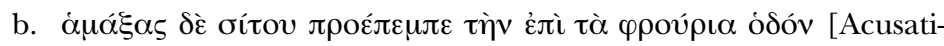
vo] «Fue enviando por delante carretas de trigo por la carretera [que conducía] a los fortines» (Jenofonte, Ciropedia II 4.18).

Las preposiciones especifican la Región espacial del Relatum: غ̇v

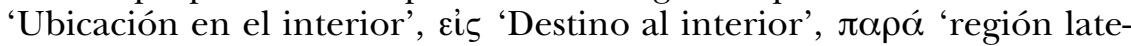

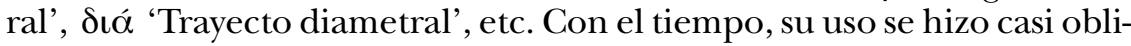
gatorio:

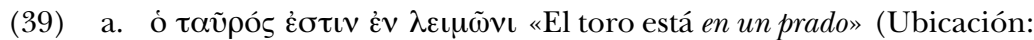
$\dot{\varepsilon} v-\mathrm{D})$.

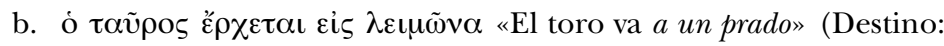
घi५-Ac).

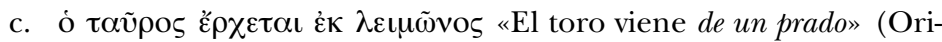
gen: $\dot{\varepsilon} \kappa-G)$.

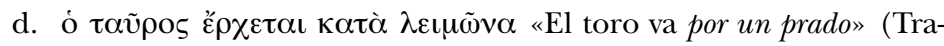
yecto: $\kappa \alpha \tau \dot{\alpha}-\mathrm{Ac})$.

Simplificando un poco la cuestión, puede decirse que, funcionalmente, los casos del griego se corresponden con las preposiciones bási-

\footnotetext{
${ }^{18}$ En lo que sigue, sólo tomaré en cuenta los usos espaciales y dejaré de lado la rica gama de sentidos figurados. Sobre todo ello, véase Luraghi 2003.
} 
cas del español (en, $a$, de, por), mientras que las preposiciones del griego -o, más exactamente las combinaciones de preposición y caso- se corresponden con las locuciones prepositivas del español, semánticamente más precisas: delante de, encima de, a través de, etcétera.

Lamentablemente, hay un cierto desajuste entre el sistema ideal que se ha descrito y los datos reales de los textos. De hecho, en la prosa clásica, sólo las preposiciones $\pi \rho o ́ \varsigma$ y $\pi \alpha \rho \alpha ́$ admiten la triple rección:

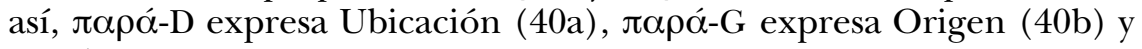

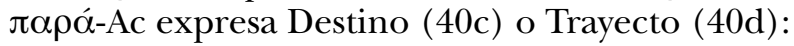

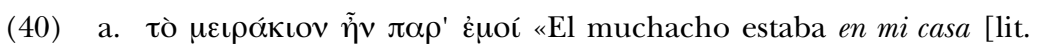
junto a mi]» (Lisias III 6).

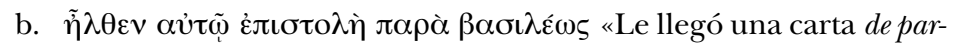
te del rey" (Jenofonte, Agesilao VIII 3.3)

c. $\pi \alpha \rho^{\prime} \dot{\varepsilon} \mu \dot{\varepsilon} \tilde{\eta} \lambda \theta \varepsilon \mu \varepsilon \tau^{\prime} \alpha u ̉ \tau o \tilde{v}$ «[Aristócrito] había venido a mi casa [lit. a mi lado] con él» (Lisias III 8).

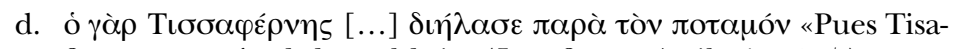
fernes avanzó a lo largo del río» (Jenofonte, Anábasis I 10.7).

Otras preposiciones sólo se combinan con un caso, que es, por ello mismo, redundante: por ejemplo, દ́v-D 'en, dentro de' (Ubicación) y عi५-Ac 'a, adentro de' (Destino) ${ }^{19}$.

Para complicar más las cosas, algunas preposiciones, en vez del dativo de Ubicación o el acusativo de Trayecto esperables, toman un genitivo que históricamente se explica como partitivo. Así, para la idea de Trayecto Homero usa indistintamente el acusativo (41a), el genitivo

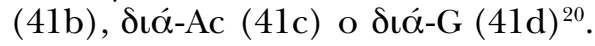

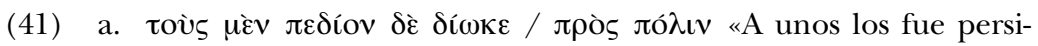
guiendo por la llanura hasta la ciudadela» (Iliada XXI 3).

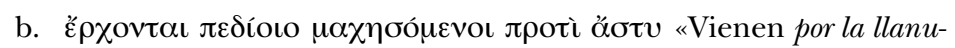
$r a$ a la ciudad a luchar» (Ilíada II 801).

\footnotetext{
19 En indoeuropeo ${ }^{*} h_{1}$ en tomaba los dos casos (cf. lat. in urbe 'en la ciudad', in urbem 'a la ciudad'). En griego, èv-Ac pervivió en unos pocos dialectos (tesalio, beocio, griego nordoccidental, eleo, arcadio). En los demás, sobre el modelo del antónimo é $\xi$ 'desde dentro de', se

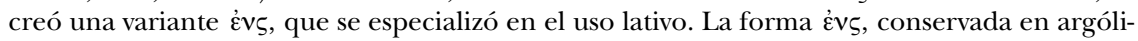

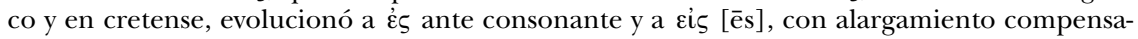
torio, ante vocal. Los dialectos tendieron a generalizar un resultado $u$ otro.

${ }^{20}$ No se percibe ya la diferencia de matiz original entre el acusativo de (41a) y (41c) («por la llanura», "por el palacio») y el genitivo partitivo de (41b) y (41d) («por una parte de la

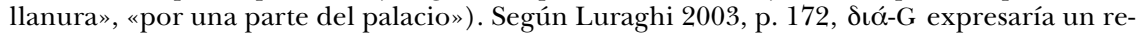
corrido rectilíneo que puede rebasar los límites del Relatum (el genitivo tendría valor ablativo), mientras que dıó-Ac expresaría un recorrido con dirección aleatoria, que no rebasa dichos límites. Esta explicación no tiene apoyo ni en los presupuestos teóricos ni en los datos.
} 


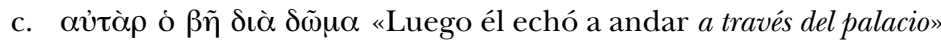
(Odisea VII 139).

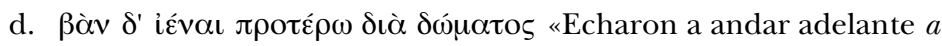
través del palacio» (Odisea XV 109).

En época clásica sólo sobrevive $\delta ı \alpha ́-G^{21}$ :

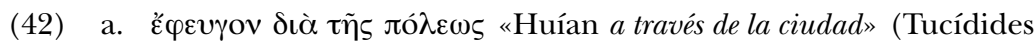
II 4.2).

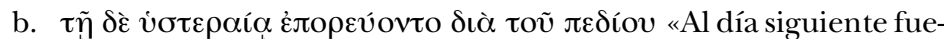
ron caminando a través de la llanura» (Jenofonte, Anábasis III 4.18).

Con estos cambios, las marcas casuales fueron perdiendo su motivación semántica. En griego moderno todas las preposiciones se construyen con acusativo, que simplemente expresa rección sintáctica ${ }^{22}$. El acusativo y el genitivo asumieron progresivamente las funciones del dativo, caso que desapareció de la lengua hablada hacia el siglo X d.C. (Humbert 1930).

Para lo que aquí nos interesa, hay que decir que el griego moderno apenas distingue formalmente entre Origen y Trayecto, que se expresan

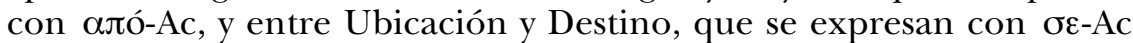
$(43)^{23}$. El sentido se deduce de la semántica del verbo y del contexto:

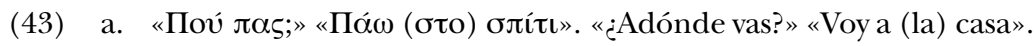

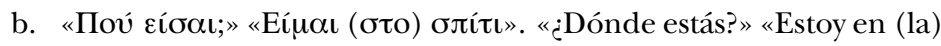
casa».

Históricamente, el adverbio đoú ‘¿dónde?, ¿adónde?’ procede de un adverbio de sentido locativo (gr. clás. đoũ ‘¿dónde?’), mientras que la construcción con $\sigma \varepsilon$ procede de un sintagma de sentido adlativo ${ }^{24}$.

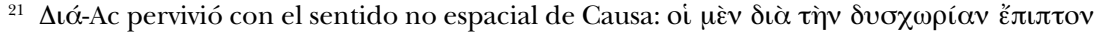
«Unos se caían por lo escabroso del terreno» (Jenofonte, Helénicas IV 3.23)

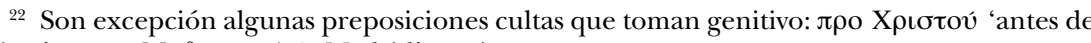

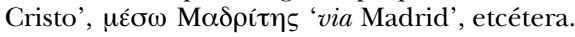

${ }^{23}$ La situación es algo más compleja. Algunos sustantivos pueden construirse en acusativo sin preposición (Holton, Mackridge y Philippaki-Warburton 1999, pp. 258-259). Salvo en el

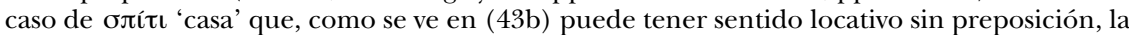

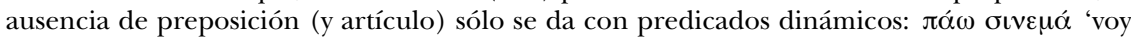

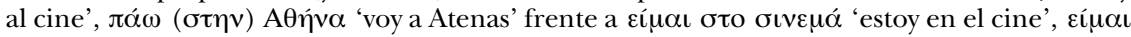

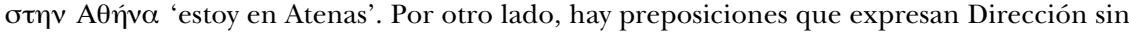

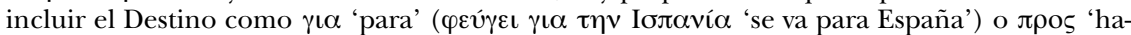
cia' ( $\pi \dot{\gamma} \gamma \varepsilon \pi \rho \varsigma_{\varsigma} \tau \eta \theta \alpha ́ \lambda \alpha \sigma \sigma \alpha$ 'fue hacia el mar') o Destino combinado con Trayecto como

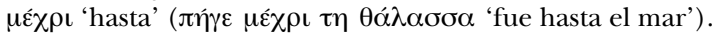

${ }^{24}$ Sincrónicamente, el conglomerado $\sigma \tau$ o se interpreta como $\sigma \varepsilon$ 'a' + $\tau$ o (ac. n. sg. del

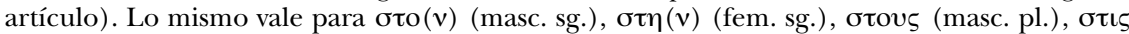

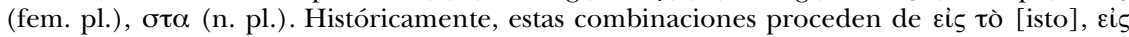
$\tau o ̀ v$ [iston], etc., con aféresis regular de la vocal átona (cf. lat. hospitium > gr. mod. блí sa'). La forma «básica» moderna $\sigma \varepsilon$ surgió secundariamente de una falsa resegmentación en

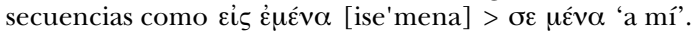


Hay indicios claros de este sincretismo en los primeros escritos cristianos, en los papiros documentales griegos de Egipto y en otros textos de la Antigüedad tardía en que aparece лoũ ‘dónde' por лoĩ 'adónde',

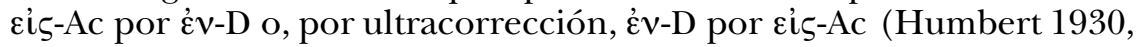
pp. 53-96):

(44) a. Kú

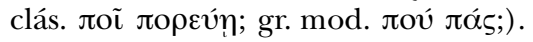

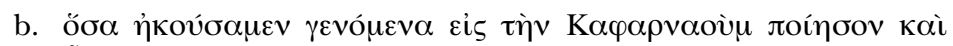

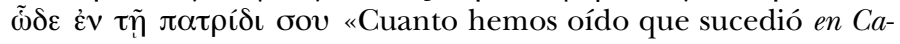
farnaúm, hazlo también aquí en tu patria» (Ev. Lucas IV 23).

\section{Verbos dinÁmicos, verbos eStÁticos, VERbos AMbiVALENTES}

Volviendo al griego de Homero y de época clásica, conviene no perder de vista que el contraste entre situaciones dinámicas y estáticas, entre verbos de movimiento y de reposo, es gradual y no absoluto. Entre los dos prototipos hay verbos que admiten dos construcciones en la misma lengua (variación intralingüística) y/o que funcionan como dinámicos en una lengua y como estáticos en otra (variación interlingüística).

Así, en griego el verbo $\pi i ́ \tau \tau \omega$ 'caer', aunque inequívocamente dinámico -no hay caídas sin desplazamiento espacial-, se construye tanto con eis-Ac (Destino) (45a) como con év-D (Ubicación) (45b):

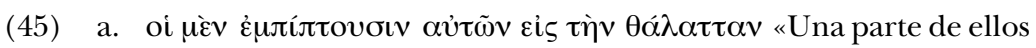
caen al mar» (Jenofonte, Helénicas IV 5.17).

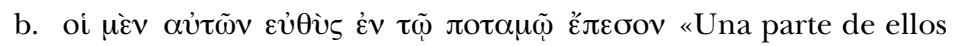
cayeron directamente al río» (Jenofonte, Helénicas III 4.24).

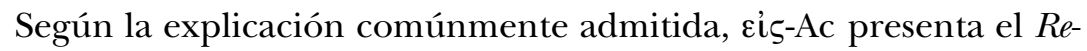
latum como Destino mientras que $\mathfrak{\varepsilon} v$-D expresa la Ubicación estática resultante del desplazamiento. La fluctuación recuerda a esp. caer al mar, pero caer en una trampa (de Bruyne 1999, p. 669).

La doble construcción también se da con verbos de «movimiento

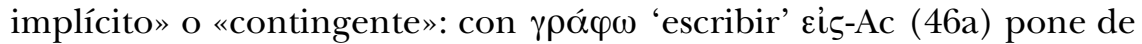
relieve el proceso de transferencia del texto a un nuevo soporte (cf. esp. pasar a limpio), mientras que ćv-D (46b) resalta la naturaleza estática del soporte.

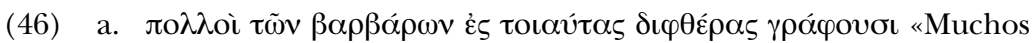
de los bárbaros escriben en pieles de ese tipo» (Heródoto V 58.16).

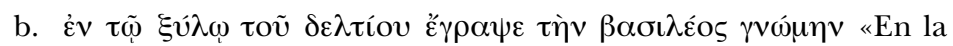
madera de la tablilla escribió la opinión del rey» (Heródoto VII 239.14). 
También $\mu \varepsilon ́ v \omega$ 'permanecer' - a priori, un verbo estático donde los haya- se combina con $\pi \alpha \rho \alpha ́$-D (Ubicación) (47a) o con $\pi \alpha \rho \alpha ́$-Ac (Destino) (47b):

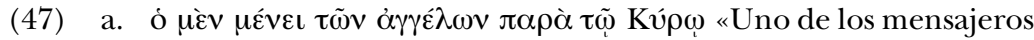
permanece junto a Ciro» (Jenofonte, Ciropedia IV 2.17).

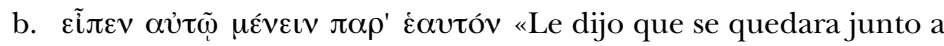
él» (Jenofonte, Ciropedia I 4.19).

Un contraste similar se da en finés entre jääd ̈ 'quedarse', que se construye con casos direccionales porque tiene sentido dinámico, y pysyä 'permanecer', que se construye con casos «estáticos» (Huumo 2007).

En Homero y en autores posteriores, í $\omega \omega,(\kappa \alpha \theta) \ddot{\varepsilon} \zeta o \mu \alpha \iota$ 'estar sen-

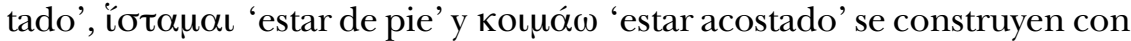
$\pi \alpha \rho \alpha ́$-D (Ubicación) o con $\pi \alpha \rho \alpha ́$-Ac (Destino):

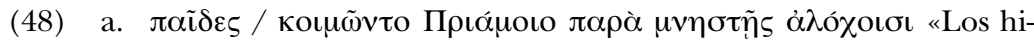
jos de Príamo estaban acostados junto a sus esposas legítimas» (Ilía$d a$ VI 245-246)

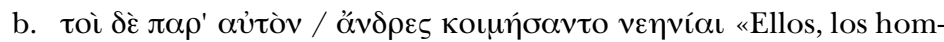
bres jóvenes, se acostaron junto a él [sc. Ulises]» (Odisea XIV 523$524)$.

Chantraine 1953, p. 122, veía en estos y en otros hechos (cf. § 11) el primer indicio del sincretismo de la Ubicación y la Dirección. En reali-

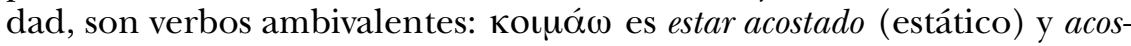
tarse (dinámico), ๕̧̌ y parado o pararse $e^{25}$.

Por último, un verbo estático puede insertarse en una situación di-

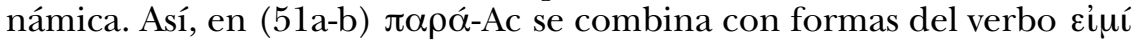
'ser, estar' porque en ambos casos se ubica un Locatum móvil.

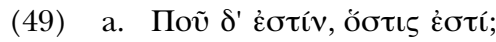

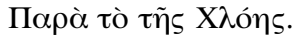

MUjER.- ¿Dónde está [ese hombre], quienquiera que sea?

Lisístrata.- Por un lado del templo de Cloe.

(Aristófanes, Lisístrata 835)

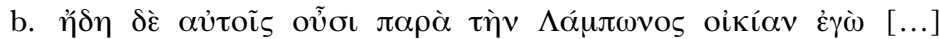

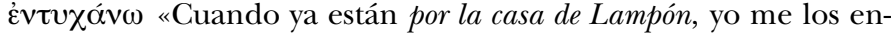
cuentro» (Lisias XVII 1).

Todos los pasajes analizados en esta sección incluyen situaciones dinámicas más o menos explícitas, que justifican el uso del acusativo. Esta ambigüedad seguramente propició el sincretismo en cuestión, pero los ejemplos en que interviene no prueban que el cambio estuviera en mar-

${ }_{25}$ Para otros casos de ambigüedad, cf. Méndez Dosuna 2007. 
cha. Hay más un problema de traducción a las lenguas modernas que una anomalía de la sintaxis del griego antiguo.

\section{MOVIMIENTO FICTICIO EN SINTAGMAS PREPOSICIONALES}

En Homero y en autores posteriores se atestiguan sintagmas preposicionales con acusativo (50-51) cuya presencia en situaciones inequívocamente estáticas resultaba hasta hace poco desconcertante:

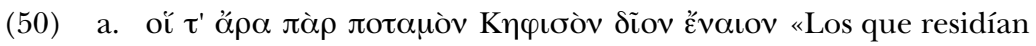
a lo largo del divino río Cefiso» (Iliada II 522).

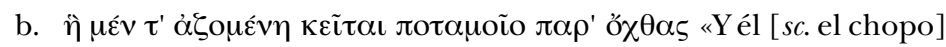
yace secándose a lo largo de las orillas del río» (Ilíada IV 487).

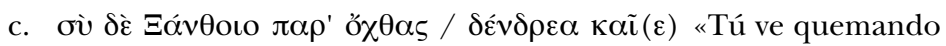
árboles a lo largo de las orillas del Janto» (Iliada XXI 337-338).

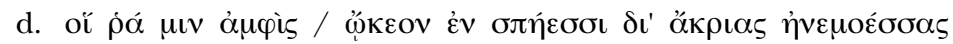
«Ellos [ $s c$. los cíclopes) vivían en torno a él [sc. Polifemo] en cuevas por cumbres ventosas» (Odisea IX 399-400).

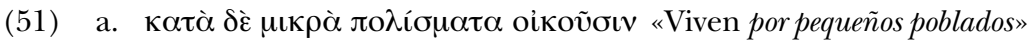
(Tucídides IV 109.5).

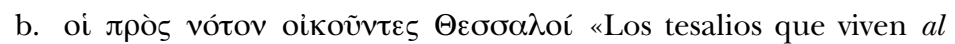
suroeste» (Tucídides II 101.2).

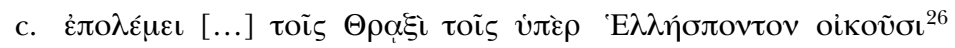
«Luchaba contra los tracios que viven al otro lado del Helesponto» (Jenofonte, Anábasis I 1.9).

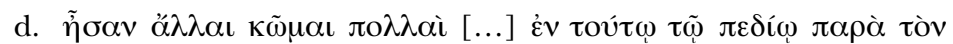

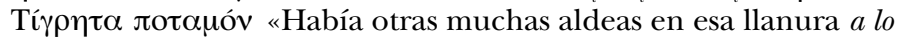
largo del río Tigris» (Jenofonte, Anábasis III 5.1).

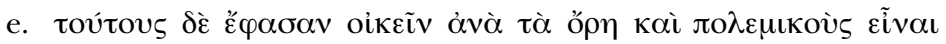
«Dijeron que los carducos habitaban por los montes arriba y que eran belicosos» (Jenofonte, Anábasis III 5.16).

Chantraine 1953, pp. 96 y 122, interpretaba que tanto $\pi \alpha \rho \alpha$-Ac en

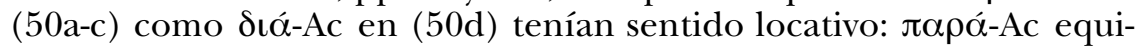
valdría a $\pi \alpha \rho \alpha ́-D$ y $\delta ı \alpha$-Ac tomaría el valor especial de 'entre, en medio de' («-parmi, au milieu de-sans mouvement», cursiva mía).

Esta deducción es érronea. Silvia Luraghi 2003 ha mostrado que los acusativos «anómalos» de (50-51) se explican como casos de movimiento ficticio, que se encuadran en el access path de Talmy 1996, 2000, del que hablamos más arriba. A una conclusión similar había llegado yo de forma independiente ese mismo año (Méndez Dosuna 2003).

${ }^{26}$ En algunos códices se lee la variante $\dot{\jmath} \pi \grave{\varepsilon} \rho$ ‘ $\mathrm{\lambda} \lambda \eta \eta \sigma \tau o ́ v \tau o v$ con genitivo. 
En (50-51) el movimiento no está en las escenas descritas, sino en el «espectador», que desplaza mentalmente su mirada por el escenario como si se tratase de un travelling cinematográfico. Los asentamientos focidios de (50a) forman un itinerario a lo largo del Cefiso. El chopo tendido en el suelo de (50b) invita a un paseo mental en paralelo a las orillas del río. Las cuevas de los cíclopes de (50d) se presentan esparci-

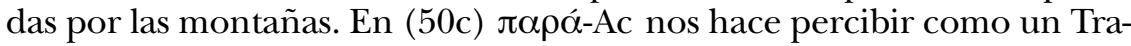
yecto los sucesivos escenarios estáticos de la quema de árboles a lo largo del Janto. Los ejemplos de (51) se prestan a interpretaciones similares.

Para referirse a los sintagmas preposicionales que expresan movimiento ficticio, Luraghi 2003 emplea sistemáticamente términos como «Location», «locational uses»y «non-directional uses». Tales etiquetas son equívocas, pues los sintagmas no expresan una Ubicación estática, sino un Trayecto de carácter dinámico.

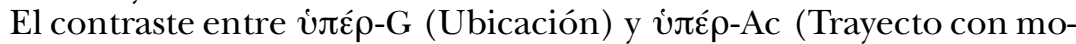
vimiento real o ficticio) se aprecia bien en los siguientes ejemplos ${ }^{27}$ :

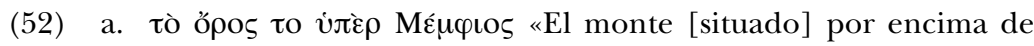
Menfis» (Heródoto II 150.3).

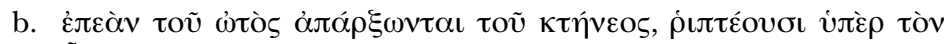
$\tilde{\omega} \mu o v$ «Cuando ofrecen [en un sacrificio] la oreja del animal, la arrojan por encima del hombro» (Heródoto IV 188).

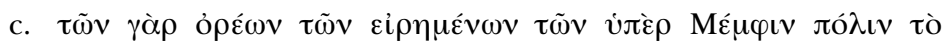
$\mu \varepsilon \tau \alpha \xi \tilde{v}$ «Lo [que hay] entre los montes [pasando] por encima de Menfis» (Heródoto II 10.3).

El fenómeno de los sintagmas preposicionales con movimiento ficticio tiene correlatos en lenguas como el inglés (53a-d) ${ }^{28}$ y el español (54a-e), aunque con características distintas en cada caso:

(53) a. The bakery is across the street from the bank «La panadería está al otro lado de la calle desde el banco».

b. The house is over the mountain «La casa está al otro lado de la montaña».

c. The house is uphill «La casa está monte arriba».

d. Oxford is to the north of London «Oxford está al norte de Londres».

(54) a. La gasolinera más cercana está río arriba, en Mayorga, mientras en Valderas, 14 kilómetros aguas abajo, está la gasolinera de Juan ${ }^{29}$.

\footnotetext{
27 Según Luraghi 2003, pp. 217 y 317, v̇ $\varepsilon \rho-G$ delinearía una relación de verticalidad (ingl. over, above 'por encima de'), mientras que en úंદ́ $\rho$-Ac dominaría el eje horizontal (ingl. beyond 'más allá de'). Esta interpretación carece de fundamento (Méndez Dosuna, ms.).

${ }^{28}$ En un español más idiomático, en ejemplos como (53a-b) usaríamos gerundios localizadores: «cruzando la calle desde el banco», "pasando la montaña».

${ }^{29}$ Agradezco a Ángela di Tullio y a Joaquín Garrido Medina el haberme llamado la atención sobre el uso con movimiento ficticio de los giros del tipo río arriba.
} 

b. La casa está al otro lado del río.
c. Hacia el norte el verde domina el paisaje.
d. El medallón está a la izquierda de la fachada.
e. Soria está al norte de Madrid.

En inglés y en español la lectura con movimiento ficticio es efecto del contexto y/o del léxico. El griego antiguo, en cambio, disponía de un procedimiento gramatical, el acusativo, para crear la ilusión de movimiento en la imaginación del receptor de modo que, dependiendo del caso que se usara, una misma preposición podía expresar una Ubi-

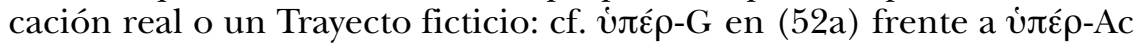
en $(52 b)$.

Como sucede con los otros procedimientos que hemos analizado (participios y gerundios localizadores, comparativas localizadoras), los sintagmas preposicionales que expresan movimiento ficticio no forman propiamente parte del núcleo del predicado. Por ello precisamente, no son incompatibles con los verbos estáticos.

En las inscripciones griegas de contenido topográfico resulta evidente la equivalencia de las comparativas localizadoras y los sintagmas preposicionales, que expresan movimiento ficticio: cf. is ò $\chi \varepsilon \iota \mu \alpha ́ \rho \rho o u s$ $\dot{\alpha}[v] \alpha ́ \gamma \varepsilon[\mathrm{l}]$ óv $\omega$ «según lleva arriba el torrente» en (27) y òv jóov «co-

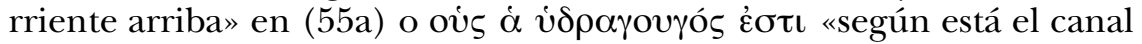

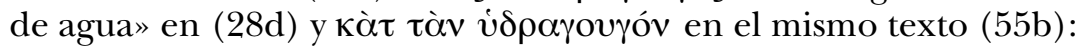

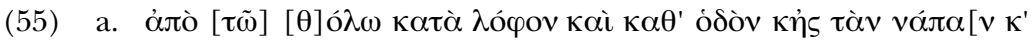

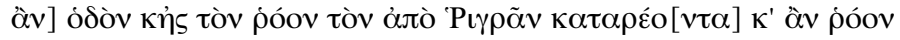

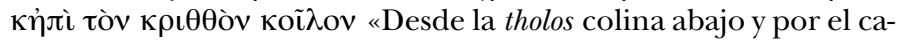
mino abajo y hasta el soto y por el camino arriba y hasta el arroyo que corre hacia abajo desde Rigras y arroyo arriba hasta el kritthós ${ }^{30}$ hueco» (IC IV 182.7ss., Gortina, 166/165 a.C.).

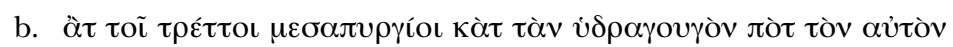

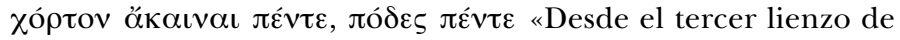
muralla por el canal de agua hasta el mismo recinto, [hay] cinco pértigas y cinco pies» (SEG XLIII 311.B 25-26, Escotusa, Tesalia, ca. 197-185 a.C.).

Por lo que se refiere a la equivalencia de los sintagmas preposicionales y los participios de punto de vista, puede compararse el uso de vंđé $\rho$-Ac para expresar movimiento ficticio en (51c) y (52b) con el participioú $\varepsilon \varepsilon \rho \beta \alpha ́ v \tau \iota$ en (56):

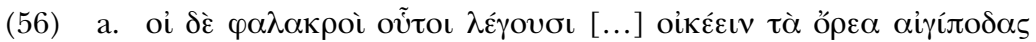

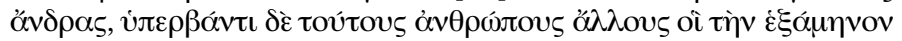

${ }^{30}$ El significado de esta palabra (¿`ustantivo? ¿adjetivo?) es incierto. 


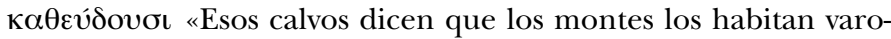
nes de pies de cabra y que pasándolos [viven] otros hombres que duermen seis meses [del año]» (Heródoto IV 25.5).

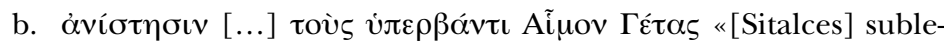
va a los Getas [que viven] pasando el monte Hemo» (Tucídides II 96.4).

Por el contrario, íđé $\rho-A c$ como expresión de un Trayecto con movimiento real se corresponde con una construcción de participio concertado con el Locatum (57):

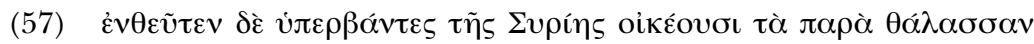
«Tras cruzar desde allí, [los fenicios] habitan la parte de Siria [situada] a lo largo de la costa» (Heródoto VII 89.8).

\section{CONCLUSIÓN}

A modo de síntesis, los tres ejemplos siguientes referidos a puertas de ciudades ( $\pi v ́ \lambda \alpha \iota)$ ilustran tres de los procedimientos de que hemos tratado: movimiento ficticio expreso (58a), sintagma preposicional combinado con dativo de punto de vista (58b) y sintagma preposicional expresando movimiento ficticio $(58 \mathrm{c})$ :

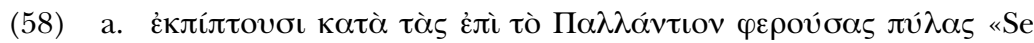
escabullen por las puertas que llevan a Palantio» (Jenofonte, Helénicas VII 2.7).

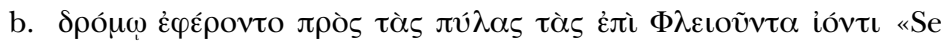
trasladaron a la carrera a las puertas [que están] yendo a Fliunte» (Jenofonte, Helénicas VII 1.18).

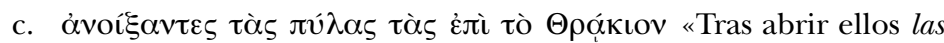
puertas de Tracio [lit. a Tracio]» (Jenofonte, Helénicas I 3.20).

En este artículo he presentado un panorama del movimiento ficticio en griego, tratando de dar una explicación global a fenómenos que, a primera vista, resultan dispares.

Todos los procedimientos estudiados coinciden en introducir un elemento dinamizador en descripciones que, de otro modo, resultarían estáticas y monótonas. Como señala Talmy 2000, pp. 171-172, el sistema cognitivo de los humanos manifiesta una inclinación natural hacia lo dinámico. Para las descripciones topográficas preferimos un tour guiado a un pase de diapositivas estáticas. 


\section{REFERENCIAS BIBLIOGRÁFICAS}

Bosque, I. y Demonte, V. (dirs.) (1999): Gramática descriptiva de la lengua espanola, Madrid, Espasa-Calpe.

BRIXHE, Cl. (1987): Essai sur le grec anatolien au début de notre ère, 2ª ed., Nancy, Presses Universitaires de Nancy.

Chantraine, P. (1953): Grammaire homérique II. Syntaxe, París, Klincksieck.

DE BRuYne, J. (1999): «Las preposiciones», en Bosque y Demonte (eds.), pp. 657-703.

FERnÁNDEZ Lagunilla, M. (1999): «Las construcciones de gerundio», en Bosque, I. y Demonte, V. (eds.), pp. 3443-3503.

Holton, D.; Mackridge, P. y Philippaki-Warburton, I. (1997): Greek: A Comprehensive Grammar of the Modern Language, Londres, Routledge.

Horrocks, G. (1997): Greek: A History of the Language and its Speakers, LondresNueva York, Longman.

Huumo, T. (2007): «Force dynamics and the fictive dynamicity of 'remaining' in Finnish», Folia Linguistica 41, pp. 73-98.

Jiménez Delgado, J. M. (2008): «Metáfora y cambios de estructura en el verbo griego antiguo», en Martínez Vázquez, R. y Jiménez Delgado, J. M., Metáfora conceptual y verbo griego antiguo, Zaragoza, Pórtico, pp. 116-179.

Langacker, R. (1999): "Virtual reality», Studies in the Linguistic Sciences 29, pp. 77-103.

LANGHOLF, V. (1977a): Syntaktische Untersuchungen zu Hippokrates-Texten, Wiesbaden, Steiner.

—, (1977b): «Unmovierte Partizipien im Griechischen», Hermes 105, pp. 290-307.

Luraghi, S. (2003): On the Meaning of Prepositions and Cases. The expression of semantic roles in Greek, Ámsterdam-Filadelfia, Benjamins.

Liddell, H. G. y ScotT, R. (1940): A Greek-English Lexicon, 9a ed., Oxford, Clarendon Press.

Mandilaras, B. (1973): The Verb in the Greek Non-Literary Papyri, Atenas, Hellenic Ministry of Culture and Sciences.

MARTínez VÁzQuez, R. (2008): «Metáfora conceptual y marco predicativo: $\varphi \varepsilon ́ \rho \omega »$, en Martínez Vázquez, R. y Jiménez Delgado, J. M., Metáfora conceptual y verbo griego antiguo, Zaragoza, Pórtico, pp. 58-115.

Matsumoto, Y. (1996): «Subjective motion in English and Japanese verbs», Cognitive Linguistics 7, pp. 183-226

MÉndez DosunA, J. (1999a): « $\Omega \varsigma$ con valor espacial en Teócrito y en inscrip-

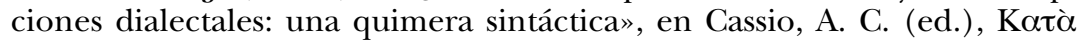
$\delta\llcorner\alpha ́ \lambda \varepsilon \kappa \tau o v . ~ A t t i$ del III Colloquio Internazionale di Dialettologia Greca (NapoliFiaiano d'Ischia, 25-28 settembre 1996) [= AION XIX (1997)], pp. 407-451.

—, (1999b): «La valeur de l'optatif oblique grec: un regard fonctionnel-typologique», en Jacquinod, B. (ed.), Les propositions complétives en grec ancien, SaintÉtienne, Publications de l'Université de Saint-Étienne, pp. 331-352.

_, (2000): Reseña de Horrocks 1997, Journal of Greek Linguistics 1, pp. 263-295.

-, (2003): "The Grammar of Subjective Motion in Greek (a plea for the (in)visible traveller)», comunicación inédita leída en el VI Congreso Internacional de Lingüística Griega, Universidad de Retimno (Creta), 20 de septiembre, 2003. 


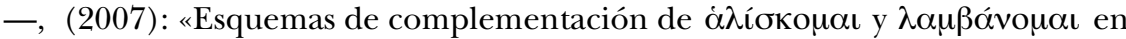
griego clásico (con especial atención a las coordenadas espacio-temporales)», en Torrego, Mํㅡㄹ E., y otros (eds.), Praedicativa II: Esquemas de complementación verbal en griego antiguo y latin, Zaragoza, Departamento de Ciencias de la Antigüedad, pp. 121-149.

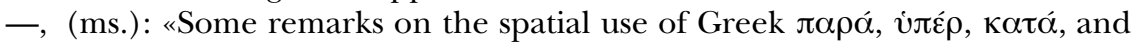
$\pi \varepsilon \rho$ í: Fictive motion and fictive meanings».

MenÉndez Pidal, R. (1911): Cantar de Mio Cid. Texto, gramática y vocabulario. Vocabulario, v. II, (5 $5^{\underline{a}}$ ed. 1977), Madrid, Espasa-Calpe.

Mirambel, A. (1961): «Participe et gérondif en grec médiéval et moderne», BSL 56, pp. 46-79.

PAVÓN Lucero, M ${ }^{\mathrm{a}}$ V. (1999): «Clases de partículas: preposición, conjunción y adverbio», en Bosque, I. y Demonte, V. (eds.), pp. 565-656.

Petersmann, H. (1979): «Zur Entwicklungsgeschichte der motionslosen Partizip im Griechischen», Die Sprache 25, pp. 144-166.

Schwyzer, E. y Debrunner, A. (1950): Griechische Grammatik. Syntax und syntaktische Stilistik, v. 2, Munich, C. H. Beck.

TALmy, L. (1996): «Fictive motion in language and ception», en Bloom, P. y otros (eds.), Language and Space, pp. 211-276, Cambridge, MA., The MIT Press.

-, (2000): Toward a Cognitive Semantics. Concept structuring systems, v. 1, Cambridge, MA., The MIT Press.

TsimpLI, I.-M. (2000): «Gerunds in Greek», Journal of Greek Linguistics 1, pp. 133169. 